\title{
Adipose tissue growth and development: the modulating role of ambient temperature
}

\author{
Michael E Symonds ${ }^{1,2}$, Mark Pope1, Ian Bloor ${ }^{1}$, James Law ${ }^{1}$, Reham Alagal and Helen Budge ${ }^{1}$ \\ ${ }^{1}$ Early Life Research Unit, Division of Child Health, Obstetrics \& Gynaecology, University of Nottingham, Nottingham, UK \\ ${ }^{2}$ Nottingham Digestive Disease Centre and Biomedical Research Centre, School of Medicine, University of Nottingham, Nottingham, UK \\ 3Department of Physical Sport Science, Princess Nourah Bint AbdulRahman University, Riyadh, Saudi Arabia
}

Correspondence should be addressed to M E Symonds: michael.Symonds@nottingham.ac.uk

\begin{abstract}
Adipose tissue is usually laid down in small amounts in the foetus and is characterised as possessing small amounts of the brown adipose tissue-specific mitochondrial uncoupling protein (UCP)1. In adults, a primary factor determining the abundance and function of UCP1 is ambient temperature. Cold exposure causes activation and the rapid generation of heat through the free flow of protons across the mitochondria with no requirement to convert ADP to ATP. In rodents, housing at an ambient temperature below thermoneutrality promotes the appearance of beige like adipocytes. These arise as discrete regions of UCP1 containing cells in white fat depots. There is increasing evidence to show that to gain credible translational results on brown and beige fat function in rodent models that they should be housed at thermoneutrality. This not only reflects the type of environment in which humans spend a majority of their time, but is in accord with the rise of global temperature caused by industrialisation and the uncontrolled burning of fossil fuels. There is now good evidence in adult humans, that stimulating brown fat can improve glucose homeostasis which can be achieved either by nutritional or pharmacological interventions. The challenge, therefore, is to establish credible developmental models in animals maintained at thermoneutrality which will elucidate the true impact of nutrition. The primary focus should fall specifically on the components of breast milk and how these modulate long term effects on brown or beige fat development and function.
\end{abstract}

\section{Key Words}

- adipose tissue

- development

- nutrition

$\checkmark$ lipid

\section{Introduction}

Adipose tissue represents one of the most dynamic organs in the body, and has an array of functions which adapt to the prevailing thermal and metabolic environment (Seale \& Lazar 2009). It acts as a site of energy storage, heat production and as an endocrine organ (Cypess et al. 2014). These different functions impact on a range of metabolic functions including appetite control, energy balance, glucose homeostasis, inflammation as well as the reproductive success (Symonds et al. 2018b). Adipose tissue is comprised of at least three different sub-types, that is, brown, beige or white fat (Kalinovich et al. 2017). These are primarily distinguished by the lack of, or by the relative abundance of uncoupling protein (UCP) 1 located on the inner mitochondrial membrane, with beige fat possessing 10-fold less UCP1 than classic brown adipocytes (Cannon \& Nedergaard 2011). When UCP1 is activated it enables the free flow of protons across the mitochondria without the need to convert ADP to ATP 
as occurs in mitochondria of all other organs (Cannon \& Nedergaard 2004). Consequently, the energy generated is used entirely to produce heat and means that the amount produced can be up to 300 times greater per unit mass than any other organ in the body (Symonds 2013). A major factor determining energy balance and thus the relative amounts of brown, beige or white adipose is ambient temperature, an adaptation that may be recruited from the first appearance of adipocytes at the foetal stage (Song et al. 2020). However, as is becoming increasingly apparent, in some but not all animal models of brown fat function, its impact on glucose homeostasis could be equally important (Arany 2019). Moreover, single-cell RNA sequencing has shown the lineage hierarchy of adipose tissue progenitors consists of distinct mesenchymal cell types (Merrick et al. 2019).

Fat deposition in the foetus is strictly limited due to the high energy cost. In most species, adipose tissue remains inert throughout gestation and is not activated until after birth (Symonds et al. 2015). The timing of maximal brown fat activation is largely dependent on maturity at birth and whether the newborn needs to 'independently' adapt to the relative cold exposure of the extra-uterine environment (Symonds et al. 2015). This will be further dependent on the balance between size at birth and the magnitude of thermal challenge experienced (Mellor \& Cockburn 1986), although the intricate link between these two factors are not fully appreciated. In the context of the rapidly changing global climate the substantial impact that temperature has in regulating adipose tissue function comes into sharper focus (Symonds et al. 2018a). The following review will investigate these inter-related factors which may be driving and further accelerate the global obesity crisis.

The primary role of adipose tissue during early life is to enable the newborn to effectively adapt to and survive the cold thermal challenge experienced immediately after birth (Symonds et al. 2015). This coincides with the onset of breathing and the post-partum surge in a large number of counter-regulatory metabolic hormones. These act synergistically to ensure adipose tissue is sufficiently stimulated and thus can attain maximal thermogenic capacity (Symonds et al. 1995). The magnitude and timing of this adaptation are dependent on relative inter-species maturity at birth (Symonds et al. 2007). In small animal species born with an immature hypothalamic-pituitary axis initially, there is a necessary dependence on huddling with littermates to maintain body temperature for the first few days of life (Nedergaard et al. 1986). By contrast in humans, brown fat is most active during childhood and then begins a gradual decline, with a potential rise around the time of puberty briefly interrupting this diminishment (Sacks \& Symonds 2013).

\section{The potential role of brown fat in metabolic homeostasis and the challenges of functional imaging}

There remains a debate as to whether the targeting of brown fat activation can be effective in preventing excess adiposity and/or related metabolic diseases such as diabetes (Cypess \& Kahn 2010). This is due in part to the difficulties in assessing brown fat function in humans, and especially in children (Symonds et al. 2012b). The 'gold standard' for assessing brown fat metabolism remains PET-CT despite the fact it involves significant exposure to radiation and in at least $50 \%$ of cases, brown fat is undetectable (Cypess et al. 2014). For these reasons, it cannot ethically be used in healthy children. Furthermore, it is not ideal for use in healthy adult subjects, who need to be in a fasted state to avoid the signal for any uptake in brown fat being 'constrained' by the more intense image in skeletal muscle (Vosselman et al. 2013). A range of other modalities are in development and the extent to which they can be adopted safely for use in infants and children remains to be established (Symonds et al. 2018a).

The most widely used technique to identify brown fat in healthy children is thermal imaging, as it is able to detect the unique bilateral hot spots for brown fat within the supraclavicular region (Law et al. 2018a). The interpretation of some studies is limited due in part to inconsistencies in both taking and processing images. Moreover, a recent review of such studies is confounded due to a clear misconception as to what constitutes a 'clinical trial' for which none have yet been conducted using thermal imaging as an outcome measure (JimenezPavon et al. 2019). To date, the majority of published studies and those included in the previous review have aimed to develop the technology and examine specific interventions in healthy subjects (Law et al. 2018a). Thermal imaging consistently detects a hot spot that collocates within the main depot of brown fat in humans, that is, the supraclavicular region and co-locates with the same area detected by PET-CT in adults (Law et al. 2019). The temperature of which declines with age and is negatively correlated with BMI percentile in children (Robinson et al. 2014) and BMI in adults (van Marken Lichtenbelt \& Schrauwen 2011). In adults, both acute and chronic cold exposure promotes heat production from 
brown fat (Sidossis \& Kajimura 2015), as well as individual nutrients or consumption of a standard meal (Scotney et al. 2017).

\section{Brown adipose tissue as a target organ to combat metabolic disease}

The extent to which stimulating brown fat can result in clinically relevant improvements in metabolism has proven difficult to demonstrate (Cypess et al. 2014). Adipose tissue dysfunction, however, has a large impact on the onset of the metabolic syndrome (Symonds et al. $2012 a$ ). This reflects the different roles of brown, white and beige fat together with depot specific responses (Kahn et al. 2019). In addition, there are complex interactions between different types of adipocytes, together with the wide range of communication signals produced (Symonds et al. 2018a). Sustainable interventions designed to modulate fat function will thus be critical in any new strategies aimed at preventing or treating complex metabolic disease. In this regard, two recent studies on adult humans suggest brown and/or beige fat could be amenable to pharmacological stimulation by using the $\beta_{3}$-adrenergic receptor agonist mirabegron (Finlin et al. 2020, O'Mara et al. 2020). In one study, daily administration of $100 \mathrm{mg}$ of mirabegron to healthy adult females $(n=14)$ for 4 weeks stimulated brown fat activity, in conjunction with an improved circulating lipid profile and insulin sensitivity (O'Mara et al. 2020). No change in overall body composition was detected, suggesting that a longer period of administration is necessary. The effect of mirabegron on brown fat appeared to map to the main known sites of the body, for example, supraclavicular region and did not include subcutaneous fat. The later finding contrasted with the findings from another study (Finlin et al. 2020) that examined the effect of administering $50 \mathrm{mg}$ of mirabegron a day for 12 weeks in obese adults (primarily female; $n=11$ and 2 males). It found no effect on classic brown fat but suggested an increase in the brown fat specific UCP1 in subcutaneous fat. This study also confirmed an improvement in glucose homeostasis and a reduction in triglyceride content in skeletal muscle fibres (Finlin et al. 2020). Taken together, these pioneering studies support the potential for targeting brown fat as a feasible intervention to improve metabolism in adult humans. Whether it would be possible to use mirabegron in children or juveniles remains to be established.

\section{Environmental temperature and its impact on reproductive health and fat mass}

The critical importance of environmental temperature in determining adipose tissue growth and development has surprisingly been ignored in the majority of studies, including those that have attempted to examine the longer-term consequences. As is becoming increasingly apparent this is a major deficiency of nearly all studies examining adipose tissue function (Cannon et al. 2020). For example, it has recently been shown that mice must be maintained at thermoneutrality and allowed to age in order to attain adipose tissue with a humanlike phenotype (de Jong et al. 2019). The fundamental impact of ambient temperature on foetal growth and development together with longer-term outcomes is further emphasized by the rise in global temperatures over the past 50 years (Solomon \& LaRocque 2019). At the same time, there appears to have been an associated decline in adult body temperature over the past 150 years (Protsiv et al. 2020). This finding was based on data from 3 cohorts and a total of $\sim 188,000$ subjects, suggesting that after correcting for age, height, weight and related variables that mean body temperature has declined by $0.03^{\circ} \mathrm{C}$ per birth decade. A number of explanations were offered of which the most plausible is the decline in metabolic rate as contemporary life in developed countries is spent predominantly at a thermoneutral temperature. In particular, the brown fat activity would be diminished (de Jong et al. 2019) and could explain the adaptation in energy balance. Moreover, with the continued increase in global temperatures, any such response may well accelerate. It is, therefore, possible that the widely accepted value of $37^{\circ} \mathrm{C}$ as 'normal human body temperature' may be too high, and has declined in parallel with the improvements in human health and longevity over the past century (de Jong et al. 2019).

Higher global temperatures are also expected to have an adverse effect on pregnancy outcomes. A recent report based on data collected in the United States between the years of 1969 and 1988 estimated that up to 25,000 infants were born earlier than expected due to maternal heat exposure (Barreca \& Schaller 2020). The same study reported an association with lower adult income in the heat exposed offspring. Given the subsequent accelerated rise in global temperatures since 1988 this problem is predicted to increase 10 -fold by the end of the century (Barreca \& Schaller 2020). Moreover, such adverse outcomes are not unexpected as animal studies 
of heat exposure have shown it has multiple adverse effects including reduced food intake and compromised placental function (Symonds \& Lomax 1992).

The continued rise in global temperatures driven by the excessive burning of fossil fuels has resulted in atmospheric carbon dioxide concentrations reaching record highs (see https://www.esrl.noaa.gov/gmd/ ccgg/trends/global.html), a further contributing factor to maternal obesity, as summarized in Fig. 1. It is apparent that in those countries with a more affluent and energy-consuming/sedentary lifestyle and thus greater gross domestic product, there is a greater incidence of maternal obesity (Fig. 1). To date, only one study in rodents has examined the impact of housing adult females at thermoneutrality prior to the onset of obesity and then through pregnancy (Albustanji et al. 2019). This has shown a modulating effect on maternal adipose tissue composition and a resetting of insulin and glucose homeostasis that would also be expected to impact on foetal fat deposition, as well as longerterm outcomes when the offspring are then reared at thermoneutrality.

\section{Ambient temperature and adipose tissue development}

The critical role of ambient housing temperature has recently been highlighted by a study in mice which has not only shown that brown fat is made up of high and low-thermogenic populations, but additionally that their relative distribution is temperature dependent (Song et al. 2020). Cold exposure (i.e. $6^{\circ} \mathrm{C}$ ) promoted the appearance of cells with high thermogenic capacity, whereas maintenance at a thermoneutral temperature had the opposite effect, compared with mice maintained at a standard (cool) temperature of $24^{\circ} \mathrm{C}$. Moreover, these subtle changes in adipocyte recruitment had no impact on body weight or fat mass and were unaffected by feeding a high-fat diet (although no details of the diet were provided) (Song et al. 2020). The impact of these adaptations on the animal's phenotype is thus unclear, especially as measurements of glucose homeostasis were not provided. This type of study emphasises the potential confounding effect of enhanced brown fat function on all rodent studies of adipose tissue development undertaken

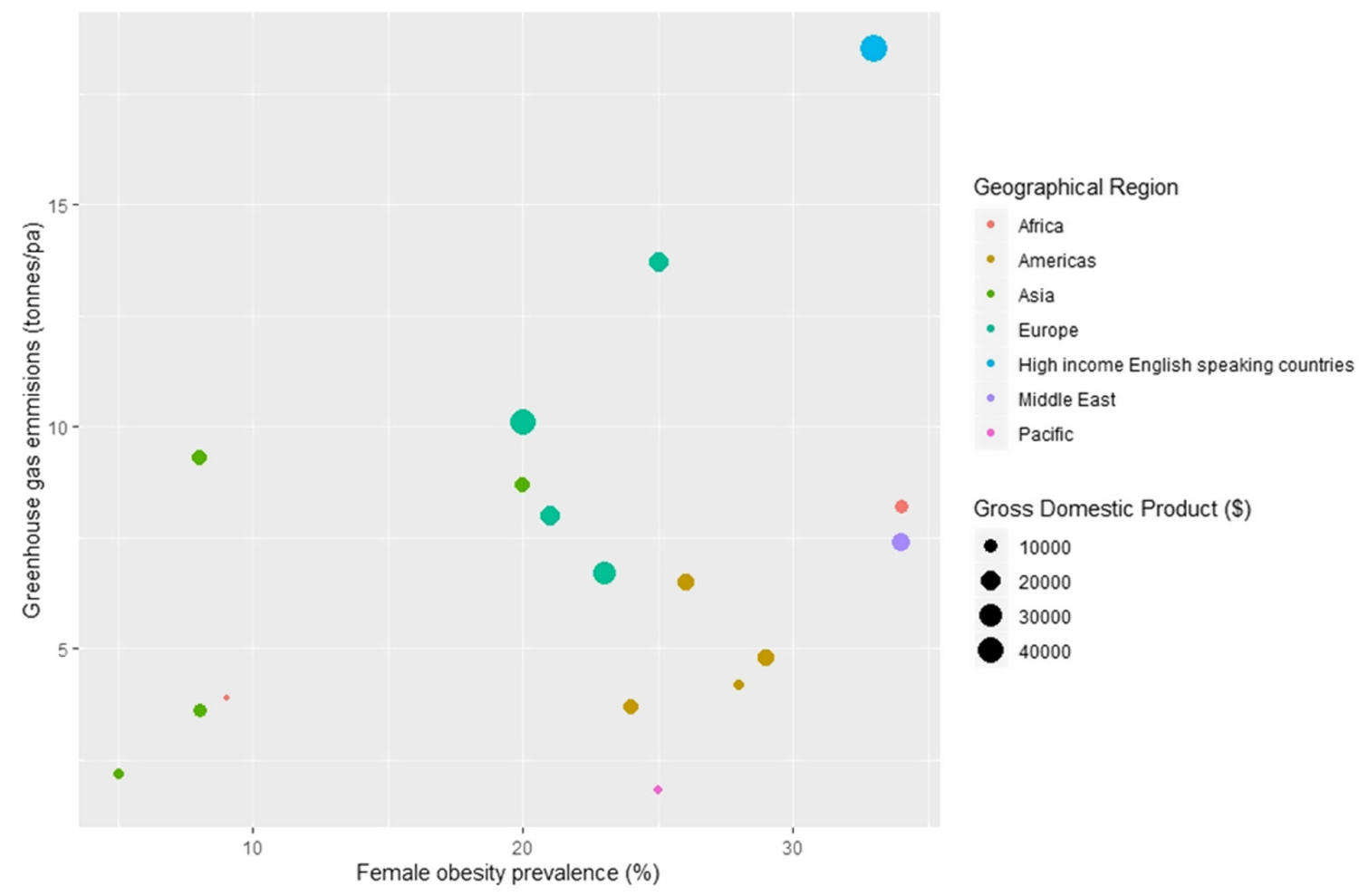

Figure 1

Summary of the relationship between the prevalence of maternal obesity and greenhouse (primarily carbon dioxide) emissions across the developed world as demonstrated by gross domestic product (with increasing circle size). Overall this illustrates, that with increased affluence, and an enhanced 'carbon footprint' is closely related to the onset of excess adiposity during reproduction. Data from Swinburn et al. (2019). 
to date, at standard (and thus cool) ambient temperatures below thermoneutrality (i.e. $27-30^{\circ} \mathrm{C}$ ).

The importance of housing temperature, together with the effects of diet and age on adipose tissue function has been further emphasised in studies that have developed the 'humanised mouse' model. This involved maintaining male mice at $30^{\circ} \mathrm{C}$ for a prolonged period from 12 to at least 37 weeks of age, whilst fed a high-fat diet. This is a practice not often followed due to the prohibitive costs of housing and husbandry for this duration of the study. Under these conditions tissues examined from interscapular, but not inguinal fat depots were very similar histologically and in their gene signatures to human supraclavicular brown fat taken from a 'healthy' male cadaver aged 22 years (de Jong et al. 2019). Thus careful consideration of cross-species age matching may be fundamental for informative future rodent modelling of adipose development and adaptation. Taken together these types of findings emphasise the plasticity of adipose tissue which has the capacity to adapt to changes in the thermal and nutritional environment to a much greater extent than any other tissue or organ (Symonds et al. 2015). Moreover, this capacity is depot dependent and reflects the dual role of adipose tissue balancing, on the one hand, energy storage within white fat, whilst on the other energy dissemination via heat production within brown and beige fat (Symonds et al. 2018a). Clearly, this type of model now needs to be fully utilised in order to gain a translatable insight into the impact of excess maternal fat mass on both the short and longer-term outcomes in the offspring. Nutrition is an impact factor contributing to early adipose tissue development (Symonds et al. 2015) and recent studies in both animals (Fainberg et al. 2018) and humans (Yu et al. 2019) suggest modulation of the diet could impact on brown adipose tissue growth.

\section{Milk composition and its impact on adipose tissue development}

It has long been recognised that feeding in the newborn is an important factor in the initiating of non-shivering thermogenesis in both small (Giralt et al. 1990) and large (Clarke \& Symonds 1998) mammals. The extent to which the composition of milk can further impact on brown fat development in early life has been further illustrated by studies showing modulation of the maternal diet during lactation can modulate brown fat composition in the offspring (Fainberg et al. 2018). One recent and fascinating developmental study (and accompanying commentary
(Gliniak \& Scherer 2019)) suggests that a unique ingredient of human breast milk, that is, alkylglycerols can promote the browning process in adipose tissue (Yu et al. 2019). Due to the practical limitations of obtaining fat samples from human infants, the study was only able to look at subcutaneous fat. It will be fascinating to see whether other depots (e.g. epicardial (Ojha et al. 2016)) show the same response. Intriguingly, the presence of alkylglycerols in milk does not appear to be extended to ruminants which could explain the rapid loss of brown fat after birth in these species, although adipose tissue composition of young sheep can still be manipulated by modifying milk composition (Fainberg et al. 2018). In addition, complementary mouse studies that show high amounts of alkylglycerols have illustrated the potential to induce browning of inguinal fat in obese but not lean mice (Yu et al. 2019). The putative mechanism is that alkylglycerols are converted into a platelet-activating factor in macrophages that infiltrate neonatal fat. In addition, M1-type macrophages have the required enzyme constitution to facilitate this process, whereas M2-type macrophages do not. The platelet-activating factor then elicits an autocrine function that ultimately stimulates IL- 6 production to promote the browning process by activating the STAT3 pathway. Fascinatingly, this response only occurred in the inguinal depot of obese mice, although the precise phenotype that results does not appear to be detailed (Yu et al. 2019). It remains to be seen whether the same response will be found in animals reared at thermoneutrality $\left(\sim 30^{\circ} \mathrm{C}\right)$ as opposed to the standard $\left(21^{\circ} \mathrm{C}\right)$, and cool temperature used in the study.

\section{Other molecular characteristics of brown fat and the potential role of the secretome in regulating brown fat function}

There is increasing recognition that brown fat has the capacity to secrete a range of hormones termed 'batokines' that may have an effect on whole-body metabolism (Villarroya et al. 2017). The first of these was identified from studies on the neonate and showed that feeding per se stimulates the release of FGF21 from the liver (Hondares et al. 2010), as well as brown fat (Hondares et al. 2011). More recently the investigation of potential batokines has been extended using high-sensitivity mass-spectrometrybased proteomics on cell media of human adipocytes derived from supraclavicular brown adipose tissue and subcutaneous white fat depots (Deshmukh et al. 2019). A total of 101 proteins were exclusively quantified within 
brown fat and included ependymin-related protein 1 (EPDR1). Initial gene knock out studies suggested that EPDR1 did impact on energy balance, possibly linked to reduced brown fat activity. However, when mice housed at thermoneutrality were injected with human recombinant EPDR1 the main response was increased physical activity, rather than a change in brown fat function. Taken together, this study indicated that EPDR1 secreted from brown fat could have a role in thermogenic determination during adipogenesis, rather than a role in modulating thermogenesis per se. In humans, EPDR1 was, however, only detectable in a small number of adult subjects ( 7 out of 30 of which 6 were male) and was only present in low amounts in three of these (Deshmukh et al. 2019). Given the higher activity of brown fat in children, this type of approach may yield very different results when undertaken in a paediatric population (Robinson et al. 2014), although clearly, it is much more difficult ethically to obtain relevant tissue samples.

miRNA, which are endogenous non-coding RNAs comprised of $\sim 22$ nucleotides can also modulate organ function by inhibiting the gene expression of individual RNAs by repressing their translation (Krol et al. 2010). With respect to adipose tissue, specific miRNA have been identified as markers of adipocyte-like cells cultured from different anatomical adipose depots in mice (Walden et al. 2009). In this regard, miR-143 was sparsely expressed in mature brown but highly expressed in mature white adipocytes. Conversely miR-206 which is highly expressed in muscle and therefore has been termed a 'myomiR', was found to be expressed in pre and mature brown adipocytes but absent from white adipocytes. Two further miRNA, miR-1 and miR-133a were also identified to follow this later pattern and also identified as brown markers. The tissue-specific distribution of these myoMIRs provides further evidence of the shared myogenic lineage in early brown fat development. It has also been proposed that microRNA sequences and their targets may vary by species, adipose tissue depot and stage of development (Ha et al. 2008). In the sheep whose fat rapidly transforms from brown to white adipose tissue over the first month of life, mir-206 appears to be largely absent from fat. There is some early expression evident in the clavicular depot but this is an order of magnitude below levels found in skeletal muscle, however, such abundance in muscle is perhaps expected of a 'myomiR'. It is noteworthy that previous studies did not compare the adipose expression levels with that of muscle (Walden et al. 2009). Gene expression in sheep adipose tissue seems to decline soon after birth (Fig. 2). In contrast, mir-143 is more abundant in both clavicular and peri-renal fat, than muscle but does not change with age. It has also been suggested that the measurement of exosomal concentration of miRNA may indicate functional differences in brown fat, but to date, this has shown very modest differences in adults (Okamatsu-Ogura et al. 2019). The increasing complexity and interaction between miRNA in preadipocytes and adipocytes could provide new insights into cardiovascular disease (Icli \& Feinberg 2017).

\section{New strategies to screen potential thermogenic compounds and test their in vivo efficacy}

It is clear that alternative strategies are required to investigate the potential of targeting brown fat as a therapeutic target for preventing obesity and diabetes in humans. One such development has been the establishment of in vitro models including those using adipocytes derived from stem cells (Velickovic et al. 2018). It offers a novel way to screen individual compounds for their thermogenic potential before subsequent testing on human volunteers as summarised in Fig. 3. These types of approaches have shown that in vitro brown or beige adipocytes retain their temperature sensitivity and potentially high-light previously over-looked endocrine roles of cytokines such as leptin. It is known that leptin can have a thermogenic effect in young sheep that is indicative of promoting brown fat function (Mostyn et al. 2002), although adult based studies have questioned this role. In vitro, however, leptin is translocated into the nucleus and this adaptation appears to be enhanced with cold exposure. Interestingly, similar responses are found in stem cells of human or murine origin, which could accelerate the identification of thermogenic compounds, especially those related to individual dietary ingredients.

There are increasing indications from animal studies that brown and beige cells could be activated through individual nutrients such as capsaicin analogues (Darre \& Domene 2015, Derbenev \& Zsombok 2016). Capsinoids exert similar effects in increasing BAT-dependent energy expenditure as does cold exposure (Luo et al. 2012). Caffeine (1,3,7-trimethylxantine), a widely consumed plant alkaloid found in coffee, and tea has been shown to aid weight loss and increased energy expenditure in both human and animals, thus reducing the risk of type 2 diabetes (Bukowiecki et al. 1983, Dulloo et al. 1989, https://joe.bioscientifica.com https://doi.org/10.1530/JOE-20-0075 (c) 2021 Society for Endocrinology Published by Bioscientifica Ltd. Printed in Great Britain 


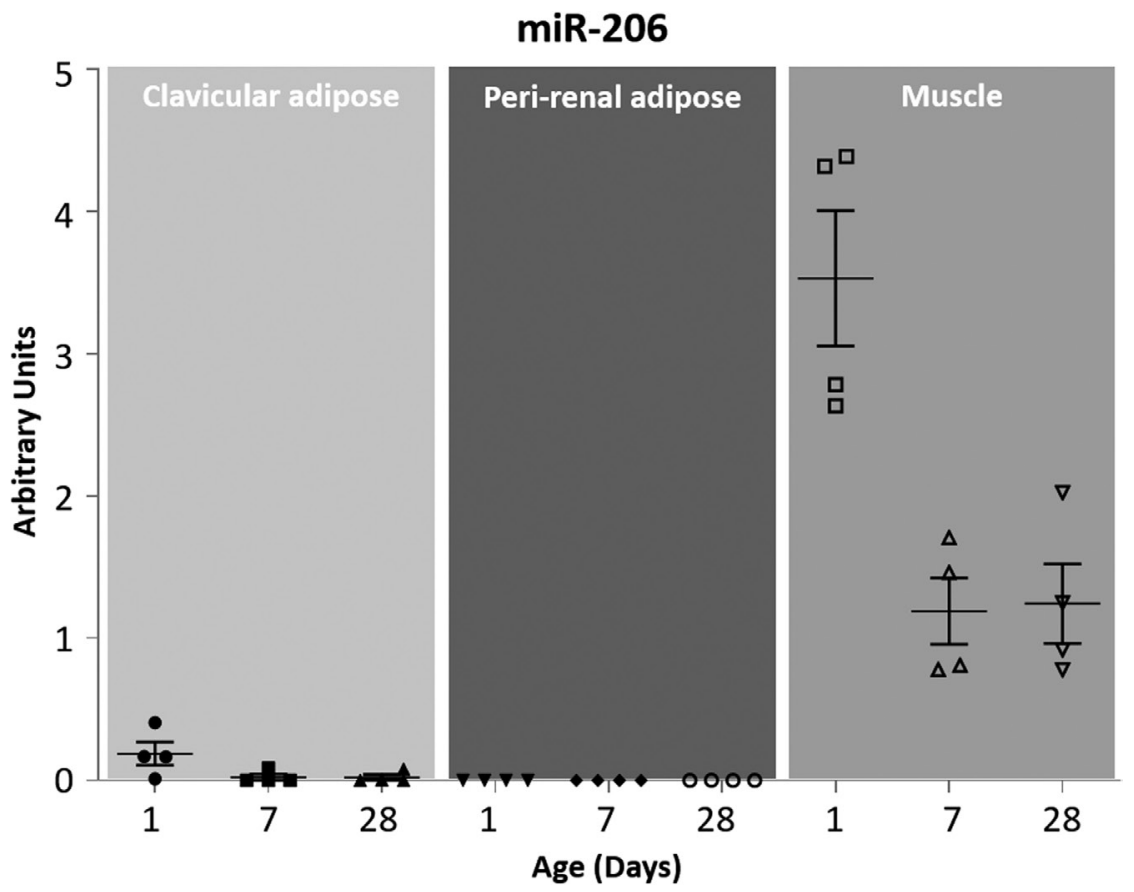

miR-143

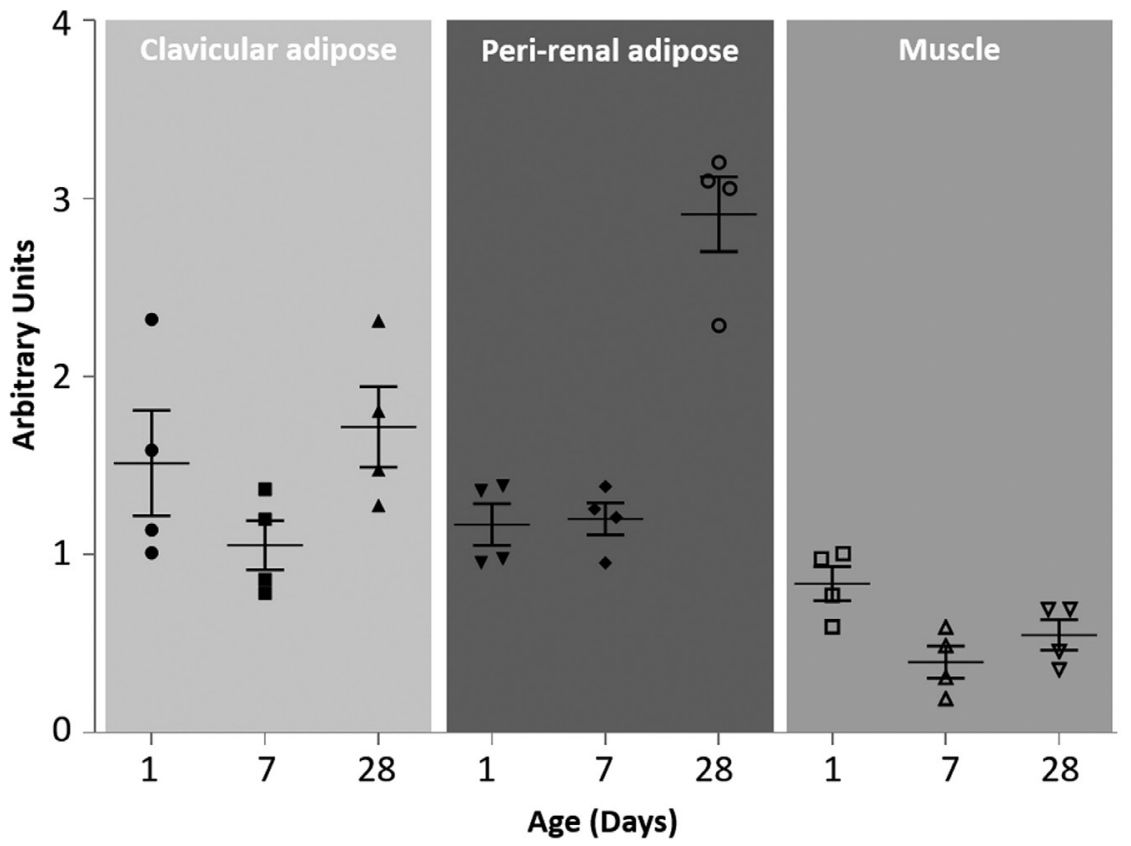

\section{Figure 2}

Summary of the development differences between the relative abundance of microRNAs 206 and 143 in young sheep between the main brown fat depots, that is, clavicular and peri-renal (Fainberg et al. 2018) and skeletal muscle that is very different to that seen in adult rodents (Walden et al. 2009).

Astrup et al. 1990, Bracco et al. 1995, Kobayashi-Hattori et al. 2005, Bhupathiraju et al. 2013). By using a stem cell model of adipocyte browning (Velickovic et al. 2018) a physiological amount of caffeine was shown to promote UCP1 function (Velickovic et al. 2019). This result was then validated by measuring the effect of the amount of caffeine normally present in a standard caffeinated beverage, that is, $65 \mathrm{mg}$ dissolved in $200 \mathrm{~mL}$ water, on healthy volunteers by thermal imaging. A thermogenic effect in supraclavicular brown fat was shown (Velickovic et al. 2019). It was assessed from an increased temperature of this region following consumption, and correlates well with the known pattern of enhanced radiolabelled glucose uptake into brown fat measured during cold exposure using PET-CT (Law et al. 2018b). It should now be possible to use a comparable approach (Fig. 3) to screen potential compounds for a thermogenic role in both adults and children. 


\section{A. In vitro screening}
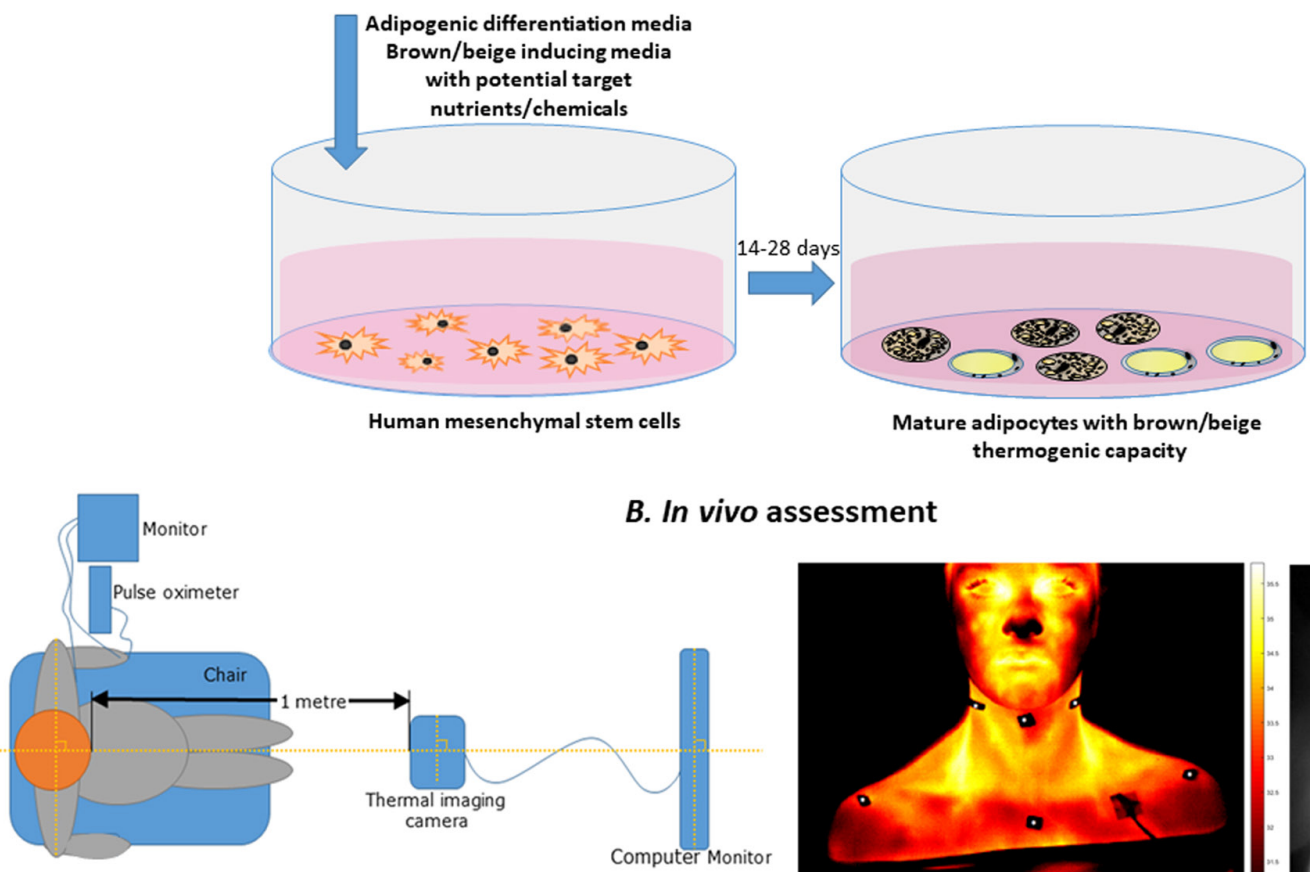

Thermal image setup; subject supplemented with nutritional stimulus to elicit brown adipose tissue response.

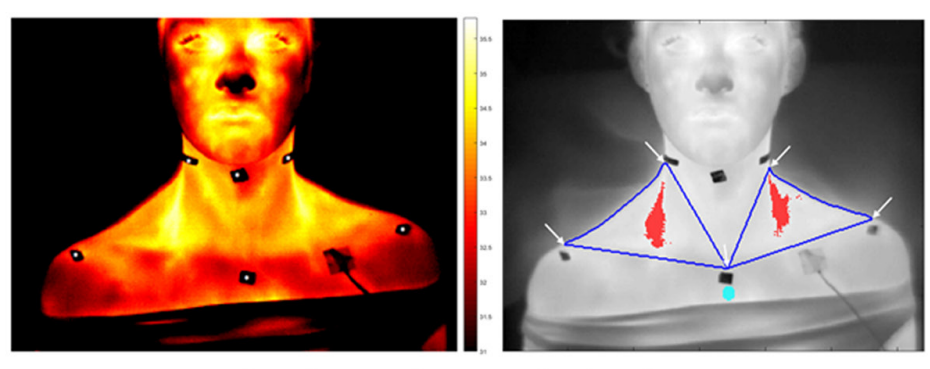

Thermal image with automated analysis, showine quantifiable brown adipose tissue thermogenic response.

Figure 3

Summary of potential techniques that can be used for (A) in vitro and (B) in vivo screening for the effectiveness of therapeutic compounds for targeting brown fat function in humans through the life cycle.

In conclusion, the past decade has seen an exponential increase in research interest and publications examining brown fat. Very few of these have focussed on development in early life or on animals maintained at thermoneutrality. Data generated by the many studies not conducted at thermoneutrality may have compromised our understanding of brown adipose biology. There is tremendous opportunity to utilise these models to correct our understanding and move forward to identify effective and credible compounds or nutrients that can enhance brown and/or beige fat function.

\section{Declaration of interest}

The authors declare that there is no conflict of interest that could be perceived as prejudicing the impartiality of this review.

\section{Funding}

The research was funded by the Deanship of Scientific Research at Princess Nourah Bint Abdulrahman University through the Fast-track Research Funding Program.

\section{References}

Albustanji L, Perez GS, AlHarethi E, Aldiss P, Bloor I, Barreto-Medeiros JM, Budge H, Symonds ME \& Dellschaft N 2019 Housing temperature modulates the impact of diet-induced rise in fat mass on adipose tissue before and during pregnancy in rats. Frontiers in Physiology 10 209. (https://doi.org/10.3389/fphys.2019.00209)

Arany Z 2019 Taking a BAT to the chains of diabetes. New England Journal of Medicine 381 2270-2272. (https://doi.org/10.1056/ NEJMcibr1911353)

Astrup A, Toubro S, Cannon S, Hein P, Breum L \& Madsen J 1990 Caffeine: a double-blind, placebo-controlled study of its thermogenic, metabolic, and cardiovascular effects in healthy volunteers. American Journal of Clinical Nutrition 51 759-767. (https://doi.org/10.1093/ajcn/51.5.759)

Barreca A \& Schaller J 2020 The impact of high ambient temperatures on delivery timing and gestational lengths. Nature Climate Change $\mathbf{1 0}$ 77-82. (https://doi.org/10.1038/s41558-019-0632-4)

Bhupathiraju SN, Pan A, Malik VS, Manson JE, Willett WC, van Dam RM \& Hu FB 2013 Caffeinated and caffeine-free beverages and risk of type 2 diabetes. American Journal of Clinical Nutrition 97 155-166. (https:// doi.org/10.3945/ajcn.112.048603)

Bracco D, Ferrarra JM, Arnaud MJ, Jequier E \& Schutz Y 1995 Effects of caffeine on energy metabolism, heart rate, and methylxanthine metabolism in lean and obese women. American Journal of Physiology 269 E671-E678. (https://doi.org/10.1152/ajpendo.1995.269.4.E671)

Bukowiecki LJ, Lupien J, Follea N \& Jahjah L 1983 Effects of sucrose, caffeine, and cola beverages on obesity, cold resistance, and adipose tissue cellularity. American Journal of Physiology $\mathbf{2 4 4}$ R500-R507. (https://doi.org/10.1152/ajpregu.1983.244.4.R500) 
Cannon B \& Nedergaard J 2004 Brown adipose tissue: function and physiological significance. Physiological Reviews 84 277-359. (https:// doi.org/10.1152/physrev.00015.2003)

Cannon B \& Nedergaard J 2011 Nonshivering thermogenesis and its adequate measurement in metabolic studies. Journal of Experimental Biology 214 242-253. (https://doi.org/10.1242/jeb.050989)

Cannon B, de Jong JMA, Fischer AW, Nedergaard J \& Petrovic N 2020 Human brown adipose tissue: classical brown rather than brite/beige? Experimental Physiology 105 1191-1200. (https://doi.org/10.1113/ EP087875)

Clarke L \& Symonds ME 1998 Thermoregulation in newborn lambs: influence of feeding and ambient temperature on brown adipose tissue. Experimental Physiology 83 651-657. (https://doi.org/10.1113/ expphysiol.1998.sp004146)

Cypess AM \& Kahn CR 2010 Brown fat as a therapy for obesity and diabetes. Current Opinion in Endocrinology, Diabetes, and Obesity 17 143-149. (https://doi.org/10.1097/MED.0b013e328337a81f)

Cypess AM, Haft CR, Laughlin MR \& Hu HH 2014 Brown fat in humans: consensus points and experimental guidelines. Cell Metabolism 20 408-415. (https://doi.org/10.1016/j.cmet.2014.07.025)

Darre L \& Domene C 2015 Binding of capsaicin to the TRPV1 ion channel. Molecular Pharmaceutics 12 4454-4465. (https://doi. org/10.1021/acs.molpharmaceut.5b00641)

de Jong JMA, Sun W, Pires ND, Frontini A, Balaz M, Jespersen NZ, Feizi A, Petrovic K, Fischer AW, Bokhari MH, et al. 2019 Human brown adipose tissue is phenocopied by classical brown adipose tissue in physiologically humanized mice. Nature Metabolism 1 830-843. (https://doi.org/10.1038/s42255-019-0101-4)

Derbenev AV \& Zsombok A 2016 Potential therapeutic value of TRPV1 and TRPA1 in diabetes mellitus and obesity. Seminars in Immunopathology 38 397-406. (https://doi.org/10.1007/s00281-015-0529-x)

Deshmukh AS, Peijs L, Beaudry JL, Jespersen NZ, Nielsen CH, Ma T, Brunner AD, Larsen TJ, Bayarri-Olmos R, Prabhakar BS, et al. 2019 Proteomics-based comparative mapping of the secretomes of human brown and white adipocytes reveals EPDR1 as a novel Batokine. Cell Metabolism 30 963.e7-975.e7. (https://doi.org/10.1016/j. cmet.2019.10.001)

Dulloo AG, Geissler CA, Horton T, Collins A \& Miller DS 1989 Normal caffeine consumption: influence on thermogenesis and daily energy expenditure in lean and postobese human volunteers. American Journal of Clinical Nutrition 49 44-50. (https://doi.org/10.1093/ajcn/49.1.44)

Fainberg HP, Birtwistle M, Alagal R, Alhaddad A, Pope M, Davies G, Woods R, Castellanos M, May ST, Ortori CA, et al. 2018 Transcriptional analysis of adipose tissue during development reveals depot-specific responsiveness to maternal dietary supplementation. Scientific Reports $\mathbf{8}$ 9628. (https://doi.org/10.1038/s41598-018-27376-3)

Finlin BS, Memetimin H, Zhu B, Confides AL, Vekaria HJ, El Khouli RH, Johnson ZR, Westgate PM, Chen J, Morris AJ, et al. 2020 The beta3adrenergic receptor agonist mirabegron improves glucose homeostasis in obese humans. Journal of Clinical Investigation $1302319-2331$. (https://doi.org/10.1172/JCI134892)

Giralt M, Martin I, Iglesias R, Vinas O, Villarroya F \& Mampel T 1990 Ontogeny and perinatal modulation of gene expression in rat brown adipose tissue. Unaltered iodothyronine 5 '-deiodinase activity is necessary for the response to environmental temperature at birth. European Journal of Biochemistry 193 297-302. (https://doi. org/10.1111/j.1432-1033.1990.tb19336.x)

Gliniak CM \& Scherer PE 2019 Critical lipids link breastfeeding to healthy adipose tissue in infancy and adulthood. Journal of Clinical Investigation 129 2198-2200. (https://doi.org/10.1172/JCI128830)

Ha M, Pang M, Agarwal V \& Chen ZJ 2008 Interspecies regulation of microRNAs and their targets. Biochimica et Biophysica Acta 1779 735-742. (https://doi.org/10.1016/j.bbagrm.2008.03.004)

Hondares E, Rosell M, Gonzalez FJ, Giralt M, Iglesias R \& Villarroya F 2010 Hepatic FGF21 expression is induced at birth via PPARalpha in response to milk intake and contributes to thermogenic activation of neonatal brown fat. Cell Metabolism 11 206-212. (https://doi. org/10.1016/j.cmet.2010.02.001)

Hondares E, Iglesias R, Giralt A, Gonzalez FJ, Giralt M, Mampel T \& Villarroya F 2011 Thermogenic activation induces FGF21 expression and release in brown adipose tissue. Journal of Biological Chemistry 286 12983-12990. (https://doi.org/10.1074/jbc.M110.215889)

Icli B \& Feinberg MW 2017 MicroRNAs in dysfunctional adipose tissue: cardiovascular implications. Cardiovascular Research 113 1024-1034. (https://doi.org/10.1093/cvr/cvx098)

Jimenez-Pavon D, Corral-Perez J, Sanchez-Infantes D, Villarroya F, Ruiz JR \& Martinez-Tellez B 2019 Infrared thermography for estimating supraclavicular skin temperature and BAT activity in humans: a systematic review. Obesity 27 1932-1949. (https://doi.org/10.1002/ oby.22635)

Kahn CR, Wang G \& Lee KY 2019 Altered adipose tissue and adipocyte function in the pathogenesis of metabolic syndrome. Journal of Clinical Investigation 129 3990-4000. (https://doi.org/10.1172/JCI129187)

Kalinovich AV, de Jong JM, Cannon B \& Nedergaard J 2017 UCP1 in adipose tissues: two steps to full browning. Biochimie 134 127-137 (https://doi.org/10.1016/j.biochi.2017.01.007)

Kobayashi-Hattori K, Mogi A, Matsumoto Y \& Takita T 2005 Effect of caffeine on the body fat and lipid metabolism of rats fed on a high-fat diet. Bioscience, Biotechnology, and Biochemistry 69 2219-2223. (https:// doi.org/10.1271/bbb.69.2219)

Krol J, Loedige I \& Filipowicz W 2010 The widespread regulation of microRNA biogenesis, function and decay. Nature Reviews: Genetics $\mathbf{1 1}$ 597-610. (https://doi.org/10.1038/nrg2843)

Law J, Morris DE, Budge H \& Symonds ME $2018 a$ Infrared thermography. Handbook of Experimental Pharmacology 251 259-282. (https://doi. org/10.1007/164_2018_137)

Law J, Morris DE, Izzi-Engbeaya C, Salem V, Coello C, Robinson L, Jayasinghe M, Scott R, Gunn R, Rabiner E, et al. 2018b Thermal imaging is a noninvasive alternative to PET/CT for measurement of brown adipose tissue activity in humans. Journal of Nuclear Medicine 59 516-522. (https://doi.org/10.2967/jnumed.117.190546)

Law JM, Morris DE, Astle V, Finn E, Muros JJ, Robinson LJ, Randell T, Denvir L, Symonds ME \& Budge H 2019 Brown adipose tissue response to cold stimulation is reduced in girls with autoimmune hypothyroidism. Journal of the Endocrine Society 3 2411-2426. (https:// doi.org/10.1210/js.2019-00342)

Luo Z, Ma L, Zhao Z, He H, Yang D, Feng X, Ma S, Chen X, Zhu T, Cao T, et al. 2012 TRPV1 activation improves exercise endurance and energy metabolism through PGC-1alpha upregulation in mice. Cell Research 22 551-564. (https://doi.org/10.1038/cr.2011.205)

Mellor DJ \& Cockburn F 1986 A comparison of energy metabolism in the new-born infant, piglet and lamb. Quarterly Journal of Experimental Physiology 71 361-379. (https://doi.org/10.1113/expphysiol.1986. sp002995)

Merrick D, Sakers A, Irgebay Z, Okada C, Calvert C, Morley MP, Percec I $\&$ Seale P 2019 Identification of a mesenchymal progenitor cell hierarchy in adipose tissue. Science $\mathbf{3 6 4}$ eaav2501. (https://doi. org/10.1126/science.aav2501)

Mostyn A, Bispham J, Pearce S, Evens Y, Raver N, Keisler DH, Webb R, Stephenson T \& Symonds ME 2002 Differential effects of leptin on thermoregulation and uncoupling protein abundance in the neonatal lamb. FASEB Journal 16 1438-1440. (https://doi.org/10.1096/fj.020077fje)

Nedergaard J, Connolly E \& Cannon B 1986 Brown adipose tissue in the mammalian neonate. In Brown Adipose Tissue, pp. 152-213. Eds P Trayhurn \& D Nicholls. London: Edward Arnold.

Ojha S, Fainberg HP, Wilson V, Pelella G, Castellanos M, May ST, Lotto AA, Sacks H, Symonds ME \& Budge H 2016 Gene pathway development in human epicardial adipose tissue during early life. JCI Insight 1 e87460. (https://doi.org/10.1172/jci.insight.87460)

Okamatsu-Ogura Y, Matsushita M, Bariuan JV, Nagaya K, Tsubota A \& Saito M 2019 Association of circulating exosomal miR-122 levels with https://joe.bioscientifica.com

https://doi.org/10.1530/JOE-20-0075 (c) 2021 Society for Endocrinology Published by Bioscientifica Ltd. Printed in Great Britain 
BAT activity in healthy humans. Scientific Reports 9 13243. (https:// doi.org/10.1038/s41598-019-49754-1)

O'Mara AE, Johnson JW, Linderman JD, Brychta RJ, McGehee S, Fletcher LA, Fink YA, Kapuria D, Cassimatis TM, Kelsey N, et al. 2020 Chronic mirabegron treatment increases human brown fat, HDL cholesterol, and insulin sensitivity. Journal of Clinical Investigation 130 2209-2219. (https://doi.org/10.1172/JCI131126)

Protsiv M, Ley C, Lankester J, Hastie T \& Parsonnet J 2020 Decreasing human body temperature in the United States since the industrial revolution. eLife 9 e49555. (https://doi.org/10.7554/eLife.49555)

Robinson L, Ojha S, Symonds ME \& Budge H 2014 Body mass index as a determinant of brown adipose tissue function in healthy children. Journal of Pediatrics 164 318.e1-322.e1. (https://doi.org/10.1016/j. jpeds.2013.10.005)

Sacks H \& Symonds ME 2013 Anatomical locations of human brown adipose tissue: functional relevance and implications in obesity and type 2 diabetes. Diabetes 62 1783-1790. (https://doi.org/10.2337/ db12-1430)

Scotney H, Symonds ME, Law J, Budge H, Sharkey D \& Manolopoulos KN 2017 Glucocorticoids modulate human brown adipose tissue thermogenesis in vivo. Metabolism: Clinical and Experimental 70 125-132. (https://doi.org/10.1016/j.metabol.2017.01.024)

Seale P \& Lazar MA 2009 Brown fat in humans: turning up the heat on obesity. Diabetes 58 1482-1484. (https://doi.org/10.2337/db09-0622)

Sidossis L \& Kajimura S 2015 Brown and beige fat in humans: thermogenic adipocytes that control energy and glucose homeostasis. Journal of Clinical Investigation 125 478-486. (https://doi.org/10.1172/ JCI78362)

Solomon CG \& LaRocque RC 2019 Climate change - a health emergency. New England Journal of Medicine $\mathbf{3 8 0}$ 209-211. (https://doi. org/10.1056/NEJMp1817067)

Song A, Dai W, Jang MJ, Medrano L, Li Z, Zhao H, Shao M, Tan J, Li A, Ning T, et al. 2020 Low- and high-thermogenic brown adipocyte subpopulations coexist in murine adipose tissue. Journal of Clinical Investigation 130 247-257. (https://doi.org/10.1172/JCI129167)

Swinburn BA, Kraak VI, Allender S, Atkins VJ, Baker PI, Bogard JR, Brinsden H, Calvillo A, De Schutter O, Devarajan R, et al. 2019 The global syndemic of obesity, undernutrition, and climate change: the Lancet Commission Report. Lancet 393 791-846. (https://doi. org/10.1016/S0140-6736(18)32822-8)

Symonds ME 2013 Brown adipose tissue growth and development. Scientifica 2013 305763. (https://doi.org/10.1155/2013/305763)

Symonds ME \& Lomax MA 1992 Maternal and environmental influences on thermoregulation in the neonate. Proceedings of the Nutrition Society 51 165-172. (https://doi.org/10.1079/pns19920026)

Symonds ME, Bird JA, Clarke L, Gate JJ \& Lomax MA 1995 Nutrition, temperature and homeostasis during perinatal development. Experimental Physiology 80 907-940. (https://doi.org/10.1113/ expphysiol.1995.sp003905)

Symonds ME, Stephenson T, Gardner DS \& Budge H 2007 Long-term effects of nutritional programming of the embryo and fetus: mechanisms and critical windows. Reproduction, Fertility, and Development 19 53-63. (https://doi.org/10.1071/rd06130)

Symonds ME, Pope M, Sharkey D \& Budge H 2012a Adipose tissue and fetal programming. Diabetologia 55 1597-1606. (https://doi. org/10.1007/s00125-012-2505-5)

Symonds ME, Henderson K, Elvidge L, Bosman C, Sharkey D, Perkins AC \& Budge $\mathrm{H} 2012 b$ Thermal imaging to assess age-related changes of skin temperature within the supraclavicular region co-locating with brown adipose tissue in healthy children. Journal of Pediatrics $\mathbf{1 6 1}$ 892-898. (https://doi.org/10.1016/j.jpeds.2012.04.056)

Symonds ME, Pope M \& Budge H 2015 The ontogeny of brown adipose tissue. Annual Review of Nutrition 35 295-320. (https://doi. org/10.1146/annurev-nutr-071813-105330)

Symonds ME, Aldiss P, Pope M \& Budge H 2018a Recent advances in our understanding of brown and beige adipose tissue: the good fat that keeps you healthy. F1000Research 7 1129. (https://doi.org/10.12688/ f1000research.14585.1)

Symonds ME, Aldiss P, Dellschaft N, Law J, Fainberg HP, Pope M, Sacks H \& Budge H 2018b Brown adipose tissue development and function and its impact on reproduction. Journal of Endocrinology 238 R53-R62. (https://doi.org/10.1530/JOE-18-0084)

van Marken Lichtenbelt WD \& Schrauwen P 2011 Implications of nonshivering thermogenesis for energy balance regulation in humans. American Journal of Physiology: Regulatory, Integrative and Comparative Physiology 301 R285-R296. (https://doi.org/10.1152/ ajpregu.00652.2010)

Velickovic K, Lugo Leija HA, Bloor I, Law J, Sacks H, Symonds M \& Sottile V 2018 Low temperature exposure induces browning of bone marrow stem cell derived adipocytes in vitro. Scientific Reports 84974. (https://doi.org/10.1038/s41598-018-23267-9)

Velickovic K, Wayne D, Leija HAL, Bloor I, Morris DE, Law J, Budge H, Sacks H, Symonds ME \& Sottile V 2019 Caffeine exposure induces browning features in adipose tissue in vitro and in vivo. Scientific Reports 9 9104. (https://doi.org/10.1038/s41598-019-45540-1)

Villarroya F, Cereijo R, Villarroya J \& Giralt M 2017 Brown adipose tissue as a secretory organ. Nature Reviews: Endocrinology 13 26-35. (https:// doi.org/10.1038/nrendo.2016.136)

Vosselman MJ, Brans B, van der Lans AA, Wierts R, van Baak MA, Mottaghy FM, Schrauwen P \& van Marken Lichtenbelt WD 2013 Brown adipose tissue activity after a high-calorie meal in humans. American Journal of Clinical Nutrition 98 57-64. (https://doi. org/10.3945/ajcn.113.059022)

Walden TB, Timmons JA, Keller P, Nedergaard J \& Cannon B 2009 Distinct expression of muscle-specific microRNAs (myomirs) in brown adipocytes. Journal of Cellular Physiology 218 444-449. (https://doi. org/10.1002/jcp.21621)

Yu H, Dilbaz S, Cossmann J, Hoang AC, Diedrich V, Herwig A, Harauma A, Hoshi Y, Moriguchi T, Landgraf K, et al. 2019 Breast milk alkylglycerols sustain beige adipocytes through adipose tissue macrophages. Journal of Clinical Investigation 129 2485-2499. (https:// doi.org/10.1172/JCI125646)

Received in final form 28 October 2020

Accepted 16 November 2020

Accepted Manuscript published online 17 November 2020 https://joe.bioscientifica.com https://doi.org/10.1530/JOE-20-0075 (c) 2021 Society for Endocrinology Published by Bioscientifica Ltd. Printed in Great Britain 